\title{
In Defense of the Internet: The Relationship between Internet Communication and Depression, Loneliness, Self-Esteem, and Perceived Social Support
}

\author{
LINDSAY H. SHAW, B.A., ${ }^{1}$ and LARRY M. GANT, C.S.W., Ph.D. ${ }^{2}$
}

\begin{abstract}
As more people connect to the Internet, researchers are beginning to examine the effects of Internet use on users' psychological health. Due in part to a study released by Kraut and colleagues in 1998, which concluded that Internet use is positively correlated with depression, loneliness, and stress, public opinion about the Internet has been decidedly negative. In contrast, the present study was designed to test the hypothesis that Internet usage can affect users beneficially. Participants engaged in five chat sessions with an anonymous partner. At three different intervals they were administered scales measuring depression, loneliness, self-esteem, and social support. Changes in their scores were tracked over time. Internet use was found to decrease loneliness and depression significantly, while perceived social support and self-esteem increased significantly.
\end{abstract}

\section{INTRODUCTION}

A CCORDING TO A SURVEY conducted by Nielsen/NetRatings, at the end of September 2001, 474 million people worldwide were connected to the Internet, ${ }^{1}$ up from 429 million only 3 months earlier. ${ }^{2}$ The rapid expansion and popularity of the Internet in today's culture has prompted researchers to examine who, exactly, is logging on.

Research shows that there is no such thing as the "typical" Internet user. Today, women make up nearly half of the Internet-user population, as opposed to even a few years ago, when it was still male-dominated. ${ }^{3,4}$ Although Internet use is associated generally with younger generations, a 1998 study found that only $6 \%$ of users were under 21,3 while in 2000 ,
4 million senior citizens were reportedly online. ${ }^{5}$ Equitability among user groups ends with age and gender, however. Overwhelmingly, Internet users are better educated that nonusers. ${ }^{3,6}$ In one study of 4,254 U.S. Internet users, only $8 \%$ had not had any post-high school education. Internet users also tend to have higher household incomes than nonusers. Finally, there is a significant racial discrepancy between those who are and are not online, with the vast majority of Internet users being white. ${ }^{3}$

Studies such as these illustrate who is using the Internet, but that is only one small piece of the puzzle for scientists who wish to understand the role of the Internet in contemporary society. Accordingly, researchers are also examining the different purposes for which

1Department of Psychology, University of California, Berkeley, California.

${ }^{2}$ School of Social Work, University of Michigan-Ann Arbor, Ann Arbor, Michigan. 
people use the Internet. Kraut and colleagues found that individuals with Internet connections in their homes use the Internet for interpersonal communication more than any other reason. ${ }^{7}$ Through chat rooms, listservs, message boards, multiuser domains (MUDs), and so on, people meet and foster relationships with people with similar interests. In many cases, these online relationships develop into "real world" relationships. 8 The Internet can also be used to maintain existing relationships. According to D'Amico, 94\% of 1,001 respondents to a survey of U.S. Internet users said that the Internet facilitated keeping in touch with friends and family; $87 \%$ of respondents reported that they use the Internet frequently for that purpose. ${ }^{6}$ Another recent study cited by Garrett found that $58 \%$ of those surveyed said the Internet has made them feel more connected to family members. ${ }^{5}$

While this seems to indicate that Internet use has positive effects on interpersonal relationships, researchers have mixed opinions about just how beneficial Internet use really is. On the one hand, the Internet allows people to overcome geographical limitations and connect with a broader and more diverse group of people than would otherwise be available. People with interests or identities that are uncommon or not easily expressed can meet similar others online. ${ }^{7,8}$ On the other hand, some argue that Internet usage, being a solitary activity, necessarily detracts from the time a person spends interacting with others, at least on a face-toface (ftf) basis, and can therefore damage interpersonal relationships.7,9 Furthermore, social scientists have yet to determine whether online relationships can be as fulfilling as ftf relationships, or whether they simply serve as less meaningful substitutes. ${ }^{10}$ In general, the prevailing attitude among researchers seems guarded, if not wary, with respect to the quality of online interactions and relationships.

Although there is some evidence to support the assertion that Internet use is detrimental, the existing studies that have established a negative correlation between users' well-being and Internet usage have not demonstrated causality. ${ }^{7-9}$ The one exception is the 1998 Internet Paradox Study, which is, to date, probably the most influential study in Internet research. In the study, Kraut and colleagues recruited 93 families who did not have Internet access in their homes at the beginning of the study. Researchers supplied each family with a personal computer, Internet access, and email accounts for individual family members. Participants' online activity was then tracked over a 2-year period. Participants were asked at the beginning of the study and again 1-2 years later to self-evaluate their social involvement and psychological wellness. Researchers operationalized social involvement to include four factors: family communication, size of local social network (people with whom participants had face-to-face interactions), size of distant social network (including face-to-face or other offline communications), and social support. Psychological wellness was determined by measures of stress, depression, and loneliness. ${ }^{7}$

The results indicated that the Internet could indeed have a negative impact on users. Internet use was positively correlated with diminishing communication between family members in the participant households. Controlling for extroversion and larger initial local networks, researchers also found that participants who used the Internet more were likely to experience a diminution of their local and distant social networks. Loneliness, depression, and daily stress were positively linked to greater Internet usage when researchers controlled for possible mediating variables. ${ }^{7}$ The researchers used path analyses to analyze each of these findings and determined that the Internet caused the observed effects.

Although none of the results were so strong as to suggest that the Internet has a categorically negative effect on users, the Internet paradox study touched a nerve in the media. ${ }^{8}$ As a result, the study received a lot of coverage and launched a wave of anti-Internet sentiment in the popular media. In addition, it caught the attention of social scientists; in the 3 years since the study's publication, researchers have taken a renewed interest in the Internet.

A predominant emerging topic of interest is the relationship between social and personality variables and Internet use. Scientists who 
attempt to link specific personality and social variables to Internet use assume that individuals are differentially motivated to pursue Internet applications; and they hypothesize that individuals' trait and social measures can be predictive of the types of Internet use in which they engage. Generally, researchers categorize the services available to users into three types or motives: information gathering, interpersonal communication, and entertainment. In one such study, Wolfradt and Doll examined the relationship between the five global personality traits (extroversion, neuroticism, openness, agreeableness, and conscientiousness), personal factors related to Internet use (attitude, self-efficacy, and innovativeness), social factors (schoolmates' and teachers' expectations), and the three broad types of Internet use among adolescents. They found that, in general, the five global traits did not predict motives for Internet use, although neuroticism was shown to predict entertainment usage significantly, and neuroticism and extroversion were predictive of interpersonal communication seeking. The three personal factors were more strongly related to all three types of Internet use, while the social factors were only significantly predictive of the information motive. There was a significant main effect for gender. ${ }^{10}$

In a related study, Hamburger and BenArtzi affirmed that neuroticism and extroversion were associated with different types of Internet use, and again, gender was shown to be a significant mediating variable. Overall, it appears that personality and social variables are at least moderately predictive of different types of Internet use, although further studies will be needed to confirm and expand on these findings. ${ }^{11}$

Research conducted since the Internet Paradox Study has not supported the notion that the Internet is altogether harmful to users. Sanders and colleagues measured depression among high-school students, anticipating that higher levels of Internet use would be associated with increased levels of depression; they found no relationship. ${ }^{9}$ Similarly, LaRose et al. undertook to explain Kraut and colleagues' assertion that Internet use causes depressions through complex path models that took into account possible mediating and moderating variables. However, after analyzing their data, they concluded that the evidence did not corroborate earlier findings. ${ }^{12}$ LaRose and colleagues subsequently argued that the depression associated with Internet use was probably due to Internet stress (stress induced by being online-for example, stress caused by difficulty establishing a network connection; for a discussion, see Eastin and Larose ${ }^{13}$ ), but that stress-induced depression was counteracted by self-efficacy. Furthermore, they found that among certain populations, depression was allayed through interpersonal communication facilitated by the Internet. ${ }^{12}$

Contrary to the idea that the Internet is a socially isolating technology, recent studies have shown that the Internet can be related positively to measures of social involvement. Hamburger and Ben-Artzi demonstrated that Internet use, as a function of trait variables, can decrease loneliness among users. ${ }^{11}$ Similarly, LaRose et al. found that Internet communication, particularly communication with known others via email, increased measures of social support. ${ }^{12}$ As a whole, the recent research suggests that it is necessary to reexamine the underlying assumption that has shaped Internet research, namely that Internet use is detrimental to users' social and psychological well-being.

The present study was designed to test whether the Internet does, in fact, negatively impact users. Participants in this study engaged in five chat sessions with an anonymous partner in a controlled environment over a period of approximately 4-8 weeks. There were two partner conditions: male-female and female-female. Measures of depression, loneliness, self-esteem, and perceived social support were taken at three intervals to assess changes over time. The researcher hypothesized that the Internet would have positive effects on participants. That is, depression and loneliness were expected to decrease over the course of the study, while self-esteem and social support were predicted to increase. No main effects or interactions were expected for partner condition or time spent in the study. 


\section{MATERIALS AND METHODS}

\section{Participants}

Participants were undergraduate students at the University of North Carolina at Chapel Hill who were enrolled in an introductory psychology course at the time of participation. In exchange for participating in this study, students received partial credit needed to fulfill a course requirement. Forty-six students enrolled in the study. Six participants failed to complete the study, so data were collected from 40 participants $(N=40)$. The participants were assigned to dyads for the purpose of chatting. There were 12 male-female dyads and eight female-female dyads.

\section{Design}

This study, which consisted of five structured Internet chat sessions between anonymous participant dyads, examined the effects of Internet usage-specifically chatting with another person-on four within-participants variables: loneliness, depression, self-esteem, and perceived social support. Social support was measured using four factors: appraisal, self-esteem, tangible (in other words, perceived material support), and belonging. Participants were each given a pre-test before the first chat session, a midtest after the second chat session, and a post-test after the fifth chat session to assess changes in these variables over the course of the study. Partner condition and amount of time from initial session to completion of the study were betweenparticipants variables.

\section{Measures}

Depression. Depression was measured using the Center for Epidemiological Studies Depression Scale (CES-D). ${ }^{14}$ The scale consists of 20 items relating to mood and behavior (e.g., "I was bothered by things that usually don't bother me," "I felt hopeful about the future," "I talked less than usual"). Subjects rate each statement on a four-point scale $(0=$ Rarely or none of the time [less than 1 day]; $3=$ Most or all of the time [5-7 days]) according to how they felt and behaved during the week prior to filling out the scale.

Loneliness. Loneliness was measured using the Revised UCLA Loneliness Scale (UCLA). ${ }^{15}$ This 20-item scale asks participants how frequently they agree with statements such as "I feel left out," "I am no longer close to anyone," and "My social relationships are superficial." Agreement is measured on a four-point scale ranging from never $(1=$ never $)$ to often $(4=$ often).

Self-esteem. Self-esteem was measured using the Texas Social Behavior Inventory (TSBI). ${ }^{16}$ The TSBI consists of 32 items relating to various aspects of one's self-concept (e.g., "I am a good mixer," "I would describe myself as indecisive," "I feel I can confidently approach and deal with anyone I meet"). Participants rated how strongly they agree or disagree with each statement on a five-point scale $(1=$ Not at all characteristic of me; $5=$ Very much characteristic of me).

Social support. Social support was measured using the Cohen-Hoberman Interpersonal Support Evaluation List (CHISEL). ${ }^{17}$ The scale is designed to measure how one evaluates the accessibility of social resources. CHISEL is comprised of 48 true/false items. It is broken down into four subscales, each relating to a different aspect of social support: self-esteem, appraisal, belonging, and tangible. The appraisal scale assesses whether a subject has someone in whom $\mathrm{s} /$ he can confide if $\mathrm{s} /$ he has a problem (e.g., "I don't know anyone at school or in town who makes my problems clearer and easier to understand"). The belonging scale measures a subject's social network (e.g., "I belong to a group at school or in town that meets regularly or does things together regularly"). The tangible scale gauges whether a subject believes that s/he can turn to someone for material aid (e.g., "I don't know anyone who would loan me several hundred dollars to pay a doctor bill or dental bill"). Each CHISEL subscale consists of 12 true/false items. 


\section{Technology}

For the purpose of this study, the experimenter, with the help of the Center for Institutional Technology at the University of North Carolina at Chapel Hill, set up a web page with chat rooms. A valid log-in name and password were required to enter the web page. Access was restricted to the experimenter and the participants. One of two logins and a password were assigned to participants prior to their first Internet sessions. Participants were not able to access the site using their ONYENS (logins used by students at the University of North Carolina at Chapel Hill to access university servers and domains), email addresses, or other screen names.

The chat rooms were administered using WebChat CT software. All interactions that occurred in the chat rooms were automatically recorded and saved. Participants gave written consent at the beginning of the study to allow their chat sessions to be recorded. As a reminder, on the home page that all participants encountered prior to each chat session, there was a message stating that the conversations would be recorded.

Participants were allowed to chat from any computer with Internet access, including personal computers in their homes or dorm rooms, and computers at the campus libraries. Originally, participants were not instructed to use a specific Internet server (e.g., Netscape, Microsoft Internet Explorer). However, it was discovered early in the study that the chat rooms could not be accessed using Microsoft Internet Explorer. Thereafter, all participants were asked to use Netscape for the duration of the experiment. Some participants also reported that they were successful in accessing the chat rooms using America Online (AOL).

\section{Procedure}

Experimental sessions were posted on a web page designed to recruit students in an introductory level psychology course at the University of North Carolina at Chapel Hill. There were no exclusion criteria. At the time of signup, students did not know the purpose of the experiment. The only information they were given was the name of the experiment ("Internet Communication"), and they were informed that the experiment required multiple sessions.

During the initial sessions, each participant met with the experimenter individually. They were first asked to read and sign an informed consent form; they were told that the purpose of the experiment was to "study issues of social interaction as they relate to Internet communication." Participants were advised that the experiment would consist of eight sessions (five on the Internet and three face-to-face with the experimenter) and that the study would not be explained in full until all eight sessions were completed.

Once the participants understood the general design, each completed a questionnaire. The questionnaire consisted of the CES-D, UCLA, the TSBI, and the CHISEL. Participants were not told what scales they were completing. They were given as much time as necessary to complete the questionnaire. The results of scales completed at this initial testing were used to record baseline measures of depression, loneliness, self-esteem, and perceived social support.

Upon completion of the scales, participants were asked to provide the experimenter with a schedule of their classes and extracurricular activities. The purpose of this was to make it easier to schedule the remaining seven sessions. Each participant was then given an instruction sheet detailing the procedure for completing the Internet sessions. Included on the instruction sheet were the URL for the study's web page, the participant's login and password, and directions for accessing the chat rooms. Males were assigned the login "subject1login;" females were assigned the login "subject2login." When the female-female dyads were chatting, the second participant to enter the chat room was automatically called "subject1login_\#2" to differentiate between the chatters. Participants were also assigned a code number with which the experimenter could later identify their conversations, and they were given specific instructions as to the procedure to follow once in the chat room, in order to standardize the format between chat sessions. 
After they completed their first face-to-face session with the experimenter, participants were partnered anonymously with another participant. None of the participants knew the identity of their partners, and they were specifically asked not to volunteer or request identifying information during the chat sessions that might jeopardize their own or their partners' anonymity. At no time were partners allowed to communicate with one another except in the chat room, where their identities were disguised by the logins. All other communication was conducted through the experimenter. Participants had the same partner for the duration of the study.

The next step was to schedule participants for two Internet sessions. They were scheduled tentatively at first; once both members of a participant couple had confirmed their availability for a particular session, the sessions were confirmed. All scheduling was accomplished using email between the experimenter and participants (every participant had a personal email account prior to entering the study), with telephone calls being used only when participants failed to respond to their emails.

On the night before or the morning of the Internet sessions, one participant in each dyad was sent three discussion questions via email. In the emails, the experimenter also reminded participants of the time the sessions were to occur and in which chat room they were meeting their partners. The discussion questions were the same for each pair in order to give the participants direction during the chat sessions as well as to standardize the interactions. The questions were intended to stimulate conversation; but, in order to avoid embarrassment or discomfort, they were not personal or objectionable in nature. Rather, participants were asked about their opinions and preferences (e.g., "If you could go out today and get any car, what kind of car would you buy? What color? What features?" and "Do you read your horoscope? How do you feel about astrology? Has a prediction ever come true for you?"). Those participants in each dyad who were not sent the discussion questions for a given session were sent emails informing them that their partners had been sent the discussion questions and also reminding them of the times and chat rooms for their sessions.

Participants were instructed to begin each session by typing their identification numbers and the date and time of the session. This helped the experimenter track each session. Once both participants in a pair were present in the chat room, the participant with the discussion questions was supposed to ask the first question and to enter the time at which they began talking about the questions. It was therefore possible to determine how long participants talked about each question, although these data were not calculated for this study. The participants then discussed the question for as long as they wanted. The same procedure was followed for the other two questions. Each Internet session followed this format.

On some occasions, one or both of the participants did not show up for a scheduled Internet session. In this case, the session was simply rescheduled at the participants' earliest convenience. While it was at least somewhat inconvenient for the participants who were "stood up," this was not considered to affect the design or outcome of the experiment.

After participants engaged in two Internet sessions, they were asked to meet with the experimenter again. At this second face-to-face interaction, the experimenter administered the same questionnaires that were completed during the initial session. Once both members of a dyad had met with the experimenter and completed the mid-test, the dyad was scheduled for three more Internet interactions in the same manner as before. The third, fourth, and fifth sessions were conducted in the same way as were the first two. After they completed the final three Internet sessions, for a total of five for the study, participants met with the experimenter one last time and again completed the same questionnaires. At the end of the final face-to-face session, participants were debriefed fully.

\section{RESULTS}

The data were analyzed in three ways. First, the mean scores for each of the scales and subscales were calculated. The mean scores indi- 
cated that the results supported the hypothesis. Scores on scales measuring negative effects (i.e., CES-D-depression-and the Revised UCLA Loneliness Scale) appeared to decrease from the pre-test to the post-test, while scores on scales indicating positive effects (i.e., CHISEL-social support-and TSBIself-esteem) increased over time.

Next, a repeated measures analysis was performed to determine whether scores changed significantly over time. The repeated measures analysis showed that changes in scores on all measures except the CHISEL self-esteem subscale were statistically significant between participants. In some cases, participants had not answered every item on the questionnaires. The repeated measures analysis eliminated incomplete data sets using listwise deletion.

Finally, the mean scores and estimated marginal means (calculated from the repeated measures analysis) were graphed to show dif- ferences between pre-test, mid-test, and posttest scores for the participant group as a whole (Figs. 1-7). In cases in which participants skipped items on a scale, mean scores were adjusted before graphing to include only scores for participants who had completed every item during all three tests.

As hypothesized, the data indicate that chatting on the Internet had beneficial effects on participants. Table 1 shows the means scores for each scale and subscale for the pre-test, mid-test, and post-test. The mean depression scores (measured by the CES-D) changed greatly between the pre-test $(X=13.20)$, midtest $(X=12.80)$, and post-test $(X=9.88)$. Likewise, scores on the UCLA Loneliness Scale declined noticeably between pre-, mid-, and post-test $(X=34.38, X=32.13, X=30.75$, respectively). The repeated measures analysis showed that the changes on both scales were statistically significant. For depression, $F(1,39)$ $=9.19, p<0.01$; for loneliness, $F(1,38)=17.79$,

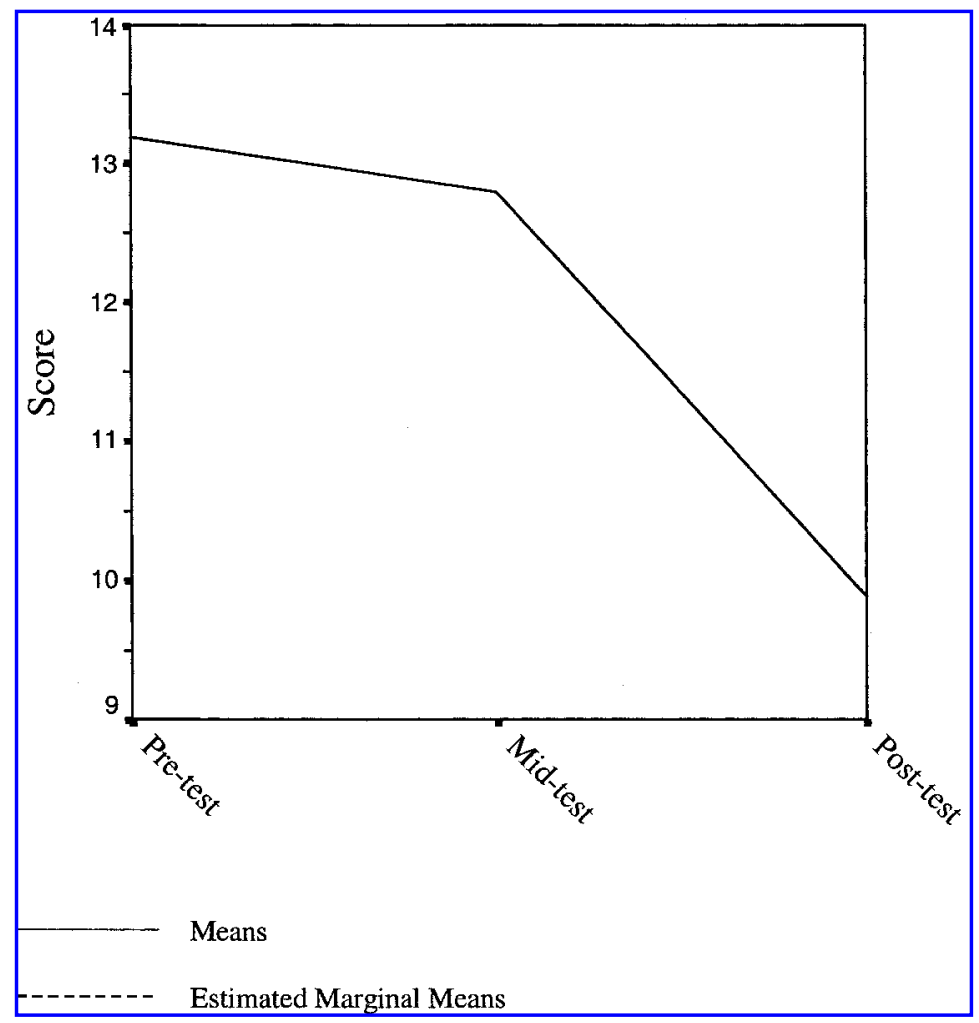

FIG. 1. Means and estimated marginal means of the center for Epidemiological Studies Depression Scale (CES-D). Note that the values of the means and the estimated marginal means were equal. 


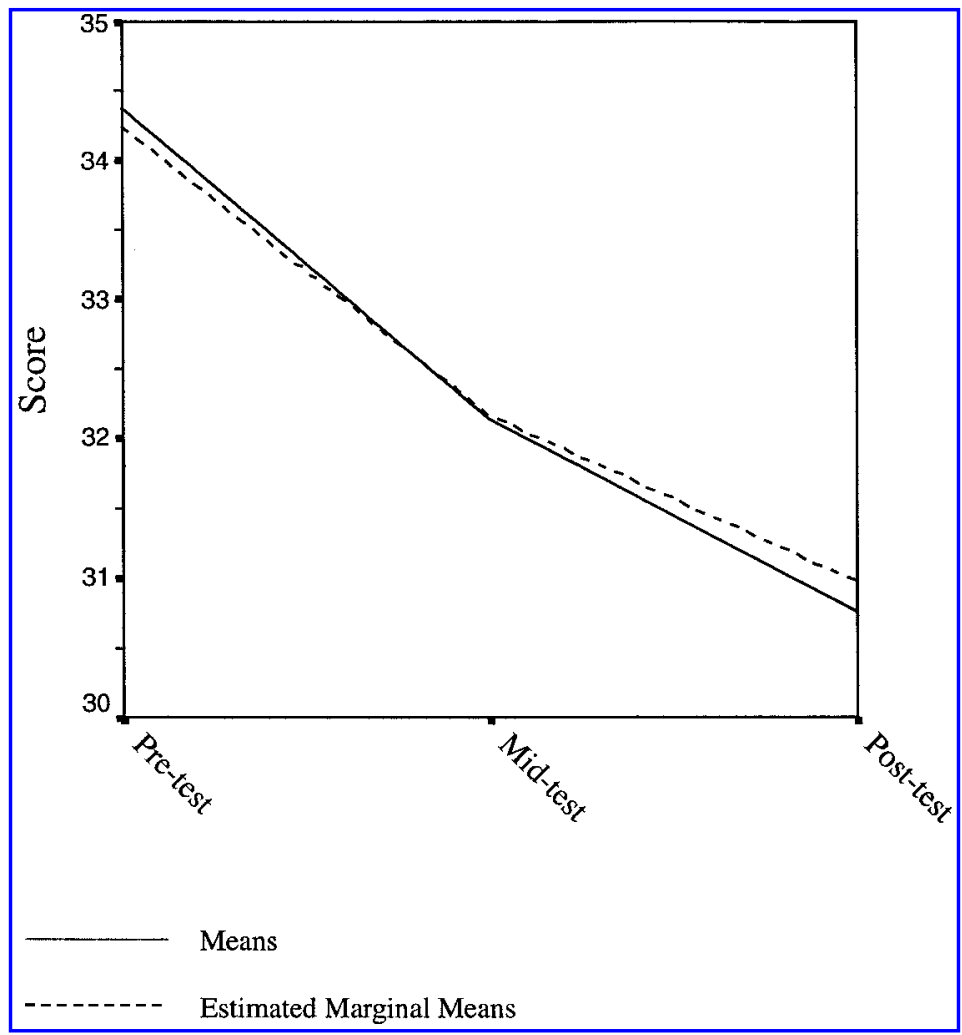

FIG. 2. Means and estimated marginal means of the revised UCLA Loneliness Scale (UCLA).

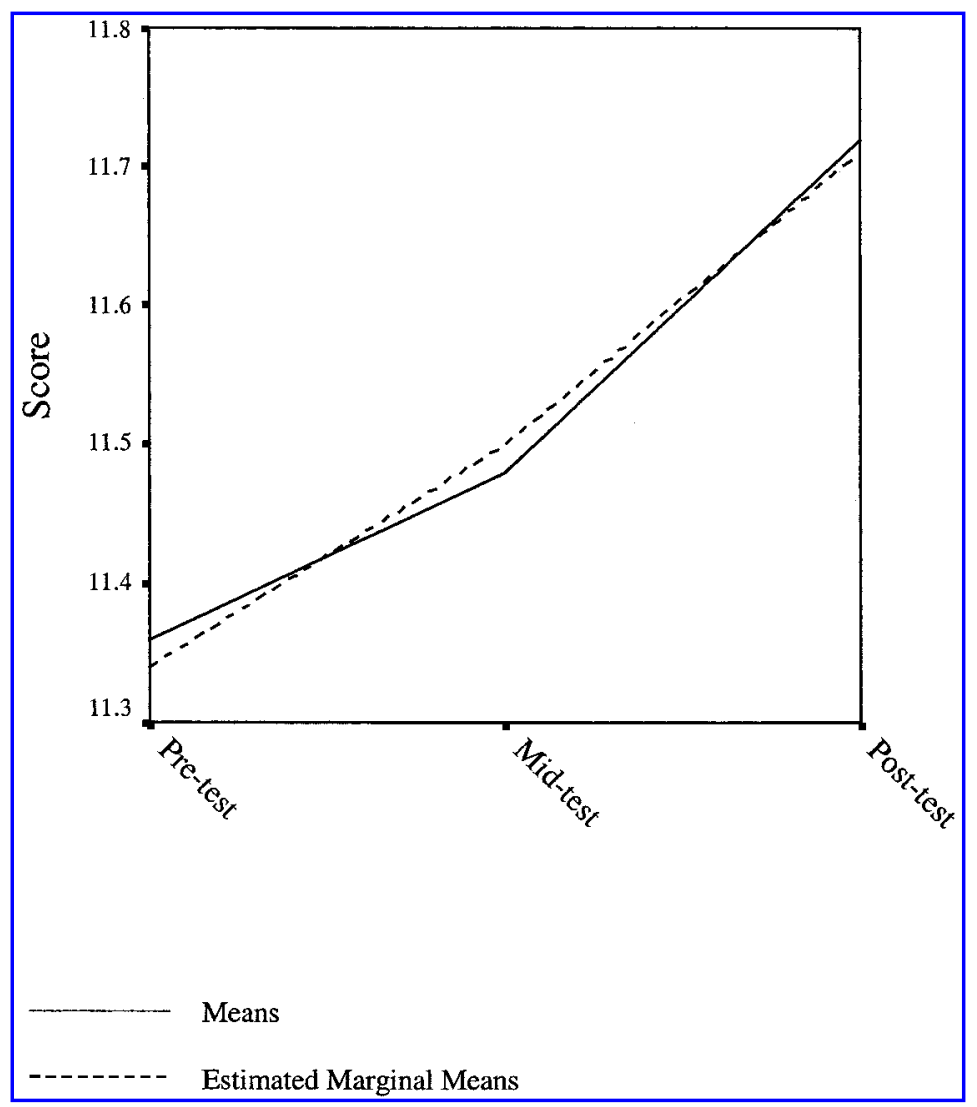

FIG. 3. Means and estimated marginal means of the appraisal subscale. 


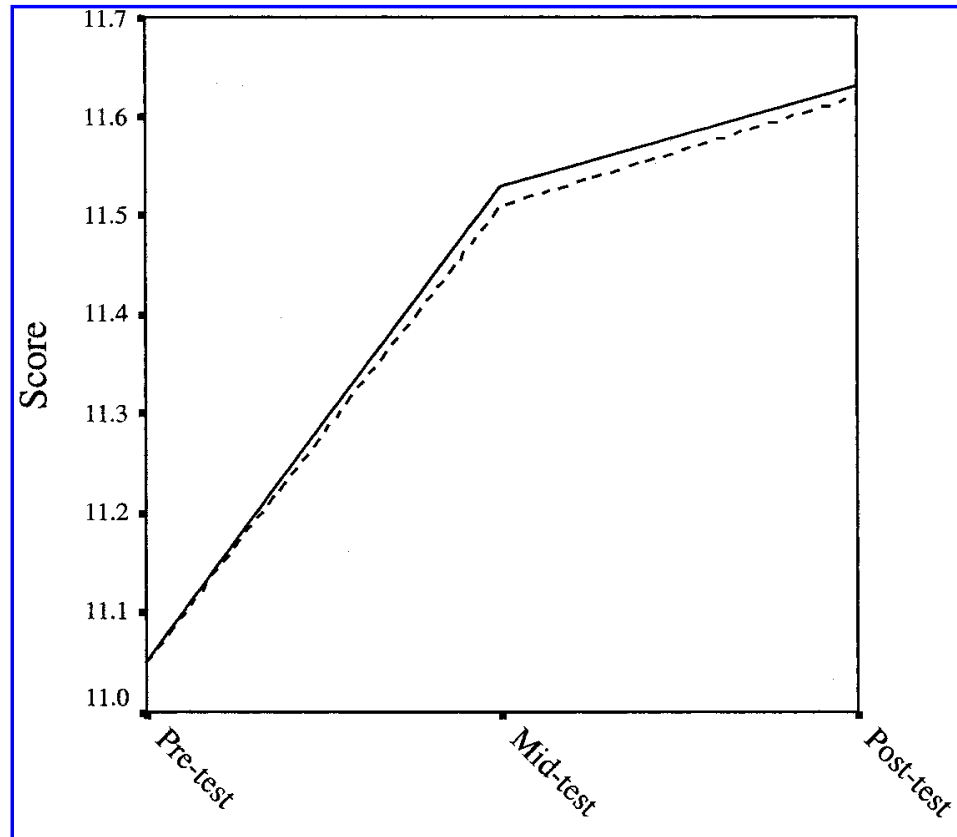

Means

Estimated Marginal Means

FIG. 4. Means and estımated marginal means of the belonging subscale.

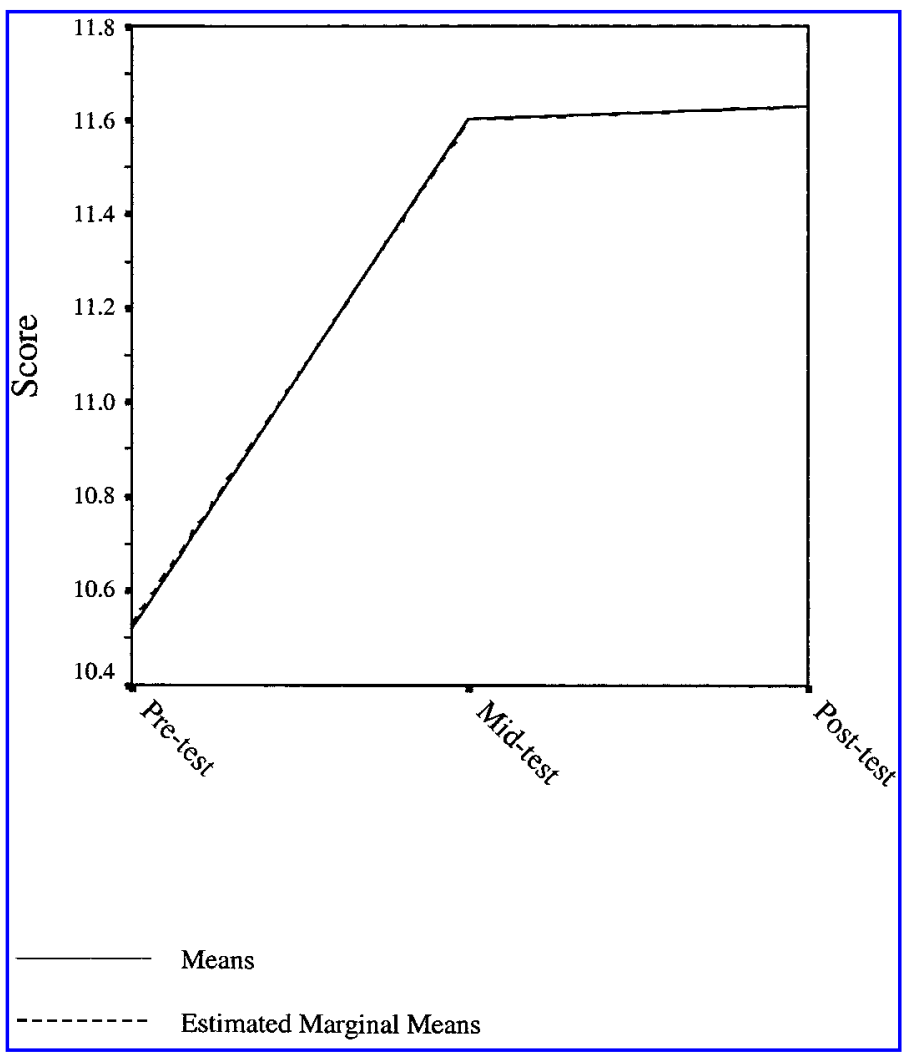

FIG. 5. Means and estimated marginal means of the tangible subscale. 


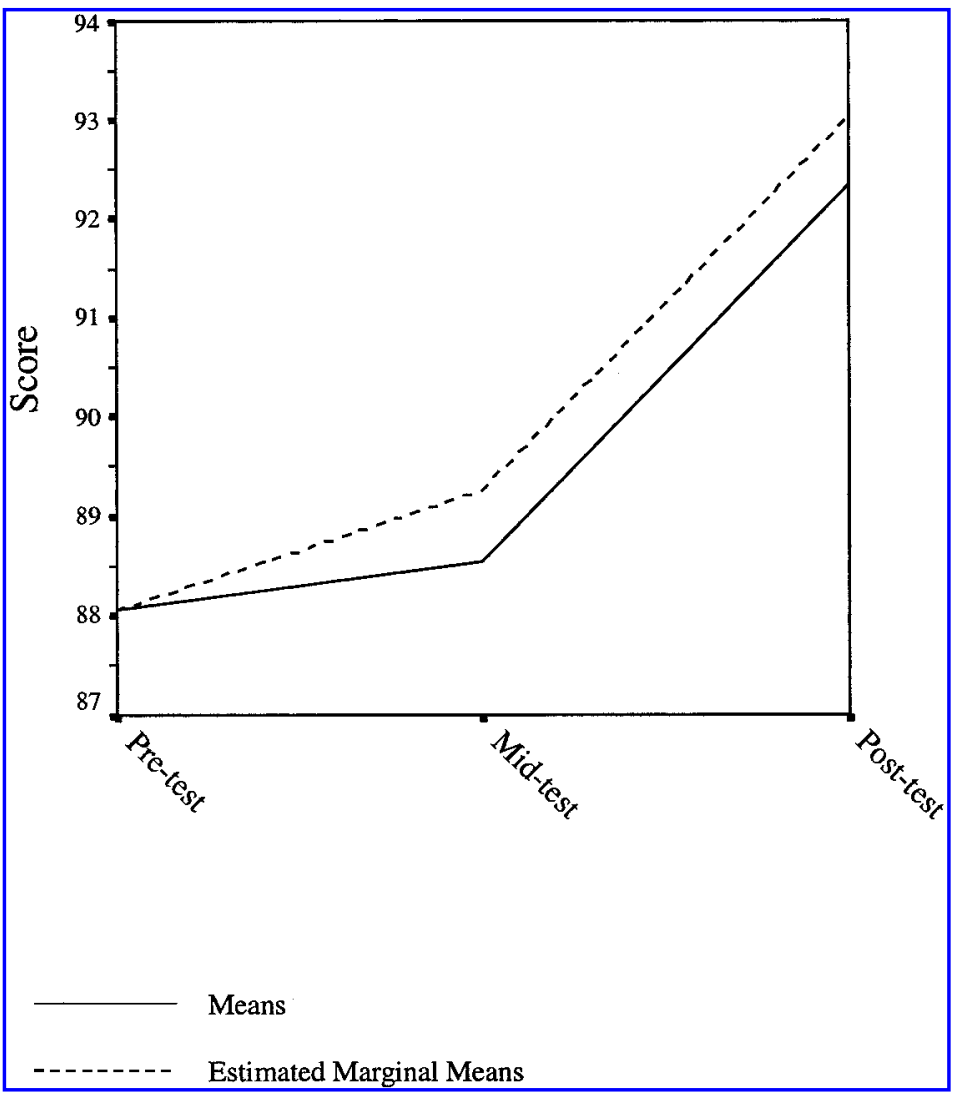

FIG. 6. Means and estimated marginal means of the Texas Social Behavior Inventory (TSBI).

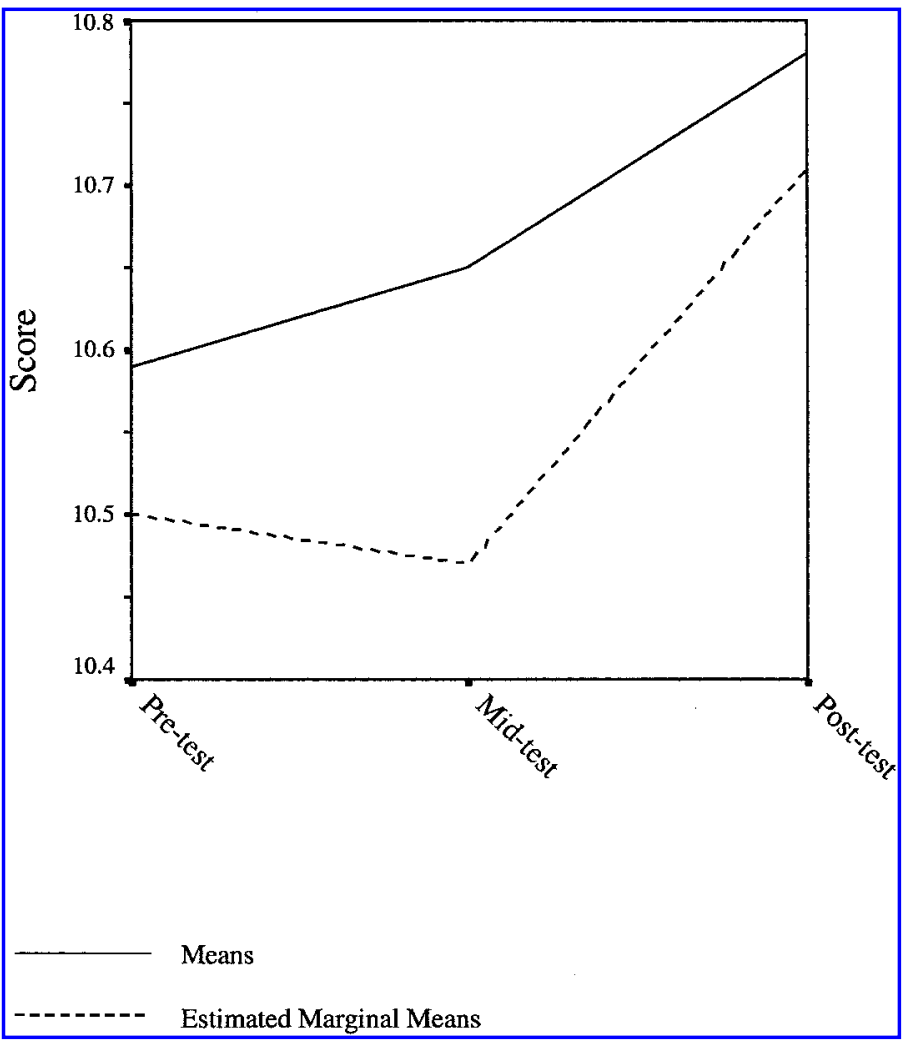

FIG. 7. Means and estimated marginal means of the self-esteem subscale. 
Table 1. Descriptive Pre-Test, Mid-Test, and Post-Test Statistics by Scale/Subscale

\begin{tabular}{|c|c|c|c|c|c|c|c|c|c|}
\hline \multirow[b]{2}{*}{ Scale } & \multicolumn{3}{|c|}{ Pre-Test } & \multicolumn{3}{|c|}{ Mid-Test } & \multicolumn{3}{|c|}{ Post-Test } \\
\hline & $N$ & $M$ & $S D$ & $N$ & $M$ & $S D$ & $N$ & $M$ & $S D$ \\
\hline CES-D & 40 & 13.20 & 7.14 & 40 & 12.80 & 8.70 & 40 & 9.88 & 7.13 \\
\hline TSBI & 39 & 88.05 & 16.71 & 40 & 88.55 & 17.74 & 40 & 92.35 & 17.53 \\
\hline UCLA & 39 & 34.38 & 9.15 & 39 & 32.13 & 8.49 & 40 & 30.75 & 8.37 \\
\hline Self-Esteem & 37 & 10.59 & 1.79 & 40 & 10.65 & 1.78 & 37 & 10.78 & 1.65 \\
\hline Appraisal & 39 & 11.36 & 0.96 & 40 & 11.48 & 0.82 & 39 & 11.72 & 0.56 \\
\hline Belonging & 39 & 11.05 & 1.23 & 40 & 11.53 & 0.82 & 40 & 11.63 & 0.81 \\
\hline Tangible & 40 & 10.53 & 1.06 & 40 & 11.60 & 0.81 & 40 & 11.63 & 1.00 \\
\hline
\end{tabular}

$p<0.001$. Figure 1 shows the changes in the mean depression scores and the estimated marginal means for the CES-D over the three times. Figure 2 shows the decline in mean loneliness scores and the estimated marginal means for the UCLA scale.

As predicted, mean scores on three of the CHISEL subscales-belonging, tangible (perceived availability of material aid), and appraisal-increased over time, indicating that participants' perceptions of social support were elevated over the course of the study. Scores on the tangible scale changed most dramatically; the mean pre-test score $(X=10.53)$ was notably lower than the scores on the midtest $(X=11.60)$ or post-test $(X=11.63)$. The mean belonging scores changed from 11.05 on the pre-test to 11.53 on the mid-test and 11.63 on the post-test. The changes on the appraisal scale were slightly less drastic; the mean scores showed small but noteworthy changes between the pre-test $(X=11.36)$, mid-test $(X=$ $11.48)$, and post-test $(X=11.72)$.

Repeated measures analyses of each CHISEL subscale resulted in statistical significance. Changes in the appraisal scale over time were more significant than the mean scores indicated, $F(1,38)=6.62, p<0.05$. The belonging scores also increased significantly, $F(1,38)=$ $10.82, p<0.01$. The results of the analysis of the tangible subscale were the most extreme, $F(1,39)=138.79, p<0.001$. The mean scores and the estimated marginal means of the appraisal, belonging, and tangible subscales are graphed in Figures 3, 4, and 5, respectively.

Self-esteem measures were also predicted to increase, and the mean scores on the TSBI and the CHISEL self-esteem subscales indicated that was the case. Scores on the TSBI showed that self-esteem did increase over time $(X=88.05, X=88.55$, and $X=92.35$ for the pre-, mid- and post-test, in that order). The mean self-esteem subscale scores also increased. The pre-test mean was 10.59 , the mid-test mean was 10.65, and the post-test mean was 10.78 .

Changes between the TSBI scores were statistically significant when tested with repeated measures analysis, $F(1,38)=10.09, p<0.01$. The shift in scores on the self-esteem subscales was not significant, $F(1,36)=1.09, p<0.5$. The difference between pre-test, mid-test, and posttest scores on the self-esteem subscale do indicate a strong trend, however, which supports the finding from the TSBI that self-esteem scores moved in the predicted direction. The changes in the mean scores and the estimated marginal means of the TSBI are graphed in Figure 6 . The changes in the mean scores and the estimated marginal means of the self-esteem subscale are graphed in Figure 7.

In accordance with the hypothesis, there were no significant interactions for amount of time spent in the study or partner condition. Table 2 shows the $F$ statistics for the interaction between scores on each of the measures and time in the study and partner condition.

\section{DISCUSSION}

Since the publication of the Internet Paradox Study in 1998, which charged that Internet use causes stress, loneliness, and depression, in- 
Table 2. Interactions between Scales and Amount of Time Spent in the Study and Partner Condition

\begin{tabular}{|c|c|c|c|c|c|c|c|}
\hline \multirow[b]{2}{*}{ Scale } & \multirow[b]{2}{*}{$N$} & \multicolumn{3}{|c|}{ Time spent in study } & \multicolumn{3}{|c|}{ Partner condition } \\
\hline & & $d f$ & $F$ & Significance & $d f$ & $F$ & Significance \\
\hline CES-D & 40 & 14 & 1.84 & 0.12 & 1 & 0.39 & 0.14 \\
\hline TSBI & 39 & 14 & 0.61 & 0.82 & 1 & 0.08 & 0.21 \\
\hline UCLA & 39 & 14 & 1.00 & 0.49 & 1 & 0.00 & 0.98 \\
\hline Self-Esteem & 37 & 14 & 0.29 & 0.99 & 1 & 0.01 & 0.92 \\
\hline Appraisal & 39 & 14 & 0.98 & 0.51 & 1 & 0.41 & 0.53 \\
\hline Belonging & 39 & 14 & 2.19 & 0.07 & 1 & 2.48 & 0.14 \\
\hline Tangible & 40 & 14 & 1.15 & 0.39 & 1 & 0.01 & 0.94 \\
\hline
\end{tabular}

vestigators have focused research efforts on examining the negative effects of Internet usage. However, the results of many recent studies have suggested that although researchers assumed initially that the Internet would affect users detrimentally, their hypotheses were not supported. Accordingly, the present study was designed to rebut earlier presumptions. Indeed, the results showed that, over the course of a 4-8-week study during which participants chatted anonymously on the Internet, loneliness and depression decreased markedly. Furthermore, participants' perceptions of social support increased, as did self-esteem.

The observed effects appear to be statistically reliable. The only result that seems somewhat suspect is the extremely strong change over time found on the tangible subscale $(F(1,39)=138.79, p<0.001)$. An examination of individual participants' data may explain this result. Because the CHISEL scale is composed of true-false items, it is less flexible than the other scales; in this case, a dramatic change on one question apparently accounts for the large effect. On Question 19, "I know someone who would loan me $\$ 100$ to help pay my tuition," only $5 \%$ of the participants $(N=2)$ answered true on the pre-test. However, on the mid- and post-test, $100 \%$ of the participants $(N=40)$ answered true to the same question. Because there was less room for variability between trials on this measure, it is possible that substantial change on a single question could produce this statistic.

This study suggests that the negative effects of the Internet have been exaggerated. In order to validate this claim, it is important to deter- mine to what extent the observed effects were the result of chatting on the Internet. Because this was a longitudinal study, albeit a short one, the possibility that there were outside variables affecting the observed trends must be considered. Depression among the participants could have decreased for reasons unrelated to the study, although it seems remote that effects as strong as those produced by this study could have been the result of random occurrences. Furthermore, the study took place during a period in the middle of a college semester for the participants, who were all students. It seems unlikely that college students' depression would decrease as they became more embroiled in the semester. Rather, it is more plausible that the decrease in depression was related to the study.

The same logic can be applied to the observed trends in the self-esteem measures. The two scales used to measure self-esteem-the TSBI and the CHISEL self-esteem subscaleboth evidenced an increase in self-esteem that is too steep to be attributed to random chance. It should be noted that participants' scores on the TSBI remained relatively stable between pretest and mid-test, and scores on the self-esteem subscale actually decreased slightly between the pre-test and mid-test, as shown in Figures 6 and 7. This suggests that Internet usage does not affect self-esteem as quickly as it affects loneliness, depression, or social support. Possibly, the significant overall increase was precipitated by decreases in loneliness and depression, which would explain why the self-esteem scores did not increase initially but only during the second half of the study. One explanation might be that Internet use does not directly af- 
fect self-esteem, but rather that it influences self-esteem through mediating variables.

Because loneliness and social support both moved in the predicted directions initially, it is likely that the changes were due to chatting on the Internet. However, it is possible that loneliness and social support effects were related to time. That is, over the course of the study, participants had opportunities to meet and form friendships with people unrelated to the study, which could lead them to feel less lonely and more socially supported. There are two flaws in this argument, though. First, if loneliness and social support increased because participants were meeting people outside the study, it would be reasonable to assume that those participants who were in the study longer should exhibit greater changes because they would have had more time in which to become acquainted with others. However, there was no significant correlation between length of time participants spent in the study and loneliness or perceived social support (as measured by tangible, appraisal, and belonging subscales).

Second, if the effects were due simply to having time to meet people, one would expect the increase from pre-test to mid-test to match the increase from mid-test to post-test approximately, since those intervals represent roughly equal periods of time. However, Figures 4 and 5 show that for the belonging and tangible subscales, that was not the case. Rather, the differences between pre- and mid-test scores were greater than the differences between mid- and post-test scores.

All of this suggests that the observed effects can be attributed to the study. McKenna and Bargh have conducted a review of Internetrelated studies and literature that might help explain the effects. ${ }^{8}$ They point out that online relationships differ fundamentally from faceto-face relationships, especially because of the anonymity accorded by the Internet. Anonymity can lead people to disclose more personal information more quickly than they do in face-to-face interactions, which probably leads to intimate relationships being a more frequent consequence of online interactions. This is likely to be compounded by the fact that computer-mediated communication eliminates the role that physical appearance plays in relationship formation, which often deters people from relationships for superficial reasons. ${ }^{8}$ Each of these factors might have contributed to the effects observed in the present study, since the participants were assigned generic login handles and were discouraged from exchanging any personal identifying information.

Moreover, online anonymity allows people to express and experiment with aspects of their identities that they might feel compelled to suppress or keep hidden in their everyday lives (e.g., radical political views, nonheterosexual orientation). ${ }^{18}$ Even individuals who are not constrained by stigma or social norms might find it difficult to meet similar others or to pursue interests offline due to geographical barriers, family and career obligations, financial burdens, and small social networks. The Internet allows users to overcome these obstacles and to manifest aspects of their personalities and identities that might otherwise remain dormant. Numerous studies have shown that people benefit both mentally and physically from expressing and defining themselves in complex, multi-faceted ways. ${ }^{18-20}$

In order to confirm these findings, it would be useful to replicate the study with a few modifications to make it even more reliable. Most importantly, future studies should include a control group. Neither this study nor the Internet Paradox Study included a sample of people with whom the participant sample could be compared, so there is no way of knowing whether the same trends found in the experimental group were present in the general population. Also, it would be helpful to control for Internet usage outside the study, as well as for other potential mediating variables such as Internet self-efficacy and familiarity.

In addition, it would be useful to conduct similar studies using different populations. Because those in the present study were college students, it would have been impossible to ask participants not to use the Internet other than for the purposes of the study. It would be extremely interesting, however, to study a sample of participants who do not otherwise use the Internet (although such a sample will be increasingly difficult to find as personal 
computers become even more common). Researchers might also replicate this study with participants who are known to be depressed, lonely, socially anxious, and so on, although such research should be undertaken with caution until the effects of Internet usage are better understood.

Also, these results will need to be replicated in field studies. In order to standardize this study, participants were given discussion questions for each chat session, and this no doubt constrained their conversations. For ethical reasons, the discussion questions were relatively innocuous; however, conversations that take place in online chat rooms are much more personal in nature. Laboratory settings have only a limited ability to approximate a real Internet environment. Although factors such as anonymity and self-disclosure, which are critical variables in Internet communication, can be manipulated experimentally, much could be learned from studying actual online interactions.

Whether it is determined that the Internet helps or harms users, research findings could have significant legal and social ramifications. The Kraut and colleagues study demonstrated that psychosocial research can substantially influence public opinion.7,8 Already, legislation has been introduced to limit the anonymity allowed on the Internet based on the belief that anonymity on the Internet can have deleterious effects. ${ }^{8}$ Because the Internet is a technology that reaches so many people, this is an area of enormous interest to the scientific and lay communities alike, and future research promises to help shape the way people view the Internet.

\section{REFERENCES}

1. Nielsen//Netratings reports that nearly 15 million people worldwide gained Internet access in Q3 (2001) [On-line]. Available: www.nielsen-netratings.com/pr/pr_011206_eratings.pdf.

2. 429 million people worldwide have Internet access, according to Nielsen//Netratings (2001) [On-line]. Available: www.nielsen-netratings.com/pr/ pr_010611_2.pdf.

3. Graphics, Visualization and Usability Center (GVUC). GVU's Tenth WWW User Survey. GVU's
WWW user surveys (1998) [On-line]. Available: www.gvu.gatech.edu/user_surveys/.

4. O'Connor E. (2000). Gauging the gender gap online [On-line]. Available: www.cnn.com/SPECIALS/ views/effect/oconnor.genders.jul11/.

5. Garrett, J.K. (2000). E-mail helps father and daughter connect across distance. [On-line]. Available: www.cnn.com/SPECIALS/views/effect/2000/11/k irtzgarrett.email.nov20/.

6. D'Amico, M.L. (1998). Internet has become a necessity, U.S. poll shows. [On-line]. Available: www.cnn. com/TECH / computing/9812/07/neednet.idg/ index.html.

7. Kraut, R., Patterson, M., Lundmark, V., et al. (1998). Internet paradox: a social technology that reduces social involvement and psychological well-being. American Psychologist 53:1017-1031.

8. McKenna, K.Y.A., \& Bargh, J.A. (2000). Plan 9 from cyberspace: the implications of the Internet for personality and social psychology. Personality and Social Psychology Review 4:57-75.

9. Sanders, C.E., Field, T.M., Diego, M., et al. (2000). The relationship of Internet use to depression and social isolation among adolescents. Adolescence 35: 237-241.

10. Wolfradt, U, \& Doll, J. (2000). Motives of adolescents to use the Internet as a function of personality traits, personal and social factors. Journal of Educational Computing Research 24:13-27.

11. Hamburger, Y.A., \& Ben-Artzi, E. (2000). The relationship between extraversion and neuroticism and the different uses of the Internet. Computers in Human Behavior 16:441-449.

12. LaRose, R., Eastin, M.S., \& Gregg, J. (2001). Reformulating the Internet paradox: Social cognitive explanations of Internet use and depression. [On-line]. Available: www.behavior.net/JOB/v1n2/paradox. html.

13. Eastin, M.S., \& LaRose, R. (2000). Internet selfefficacy and the psychology of the digital divide. [On-line]. Available: www.ascusc.org/jcmc/vol6/ issue1/eastin.html.

14. Radloff, L.S. (1977). The CES-D Scale: a self-report depression scale for research in the general population. Applied Psychological Measurement 1:385-401.

15. Russell, D., Peplau, L., \& Cutrona, C.E. (1980). The Revised UCLA Loneliness Scale: Concurrent and discriminant validity evidence. Iournal of Personality and Social Psychology 39:472-480.

16. Helmreich, R., \& Stapp, J. (1974). Short forms of the Texas Social Behavior Inventory (TSBI), an objective measure of self-esteem. Bulletin of the Psychonomic Society 4:473-475.

17. Cohen, S., \& Hoberman, H. (1983). Positive events and social supports as buffers of life-change stress. Journal of Applied Social Psychology 13:99-125.

18. McKenna, K.Y.A., \& Bargh, J.A. (1998). Coming out in the age of the Internet: identity "de-marginaliza- 
tion" through virtual group participation. Journal of Personality and Social Psychology 75:681-694.

19. Linville, P.W. (1985). Self-complexity and affective extremity: don't put all your eggs in one cognitive basket. Social Cognition 3:94-120.

20. Verbrugge, L. (1983). Multiple roles and physical health of women and men. Journal of Health and Social Behavior 24:16-30.
Address reprint requests to:

Larry Gant University of Michigan 3780 School of Social Work Building 1080 S. University Ann Arbor, MI 48109 


\section{This article has been cited by:}

1. Junghyun Kim, Robert LaRose, Wei Peng . Loneliness as the Cause and the Effect of Problematic Internet Use: The Relationship between Internet Use and Psychological Well-BeingLoneliness as the Cause and the Effect of Problematic Internet Use: The Relationship between Internet Use and Psychological Well-Being. CyberPsychology Behavior, ahead of print. [Abstract] [PDF] [PDF Plus]

2. Mu Hu . 2009. Will Online Chat Help Alleviate Mood Loneliness?Will Online Chat Help Alleviate Mood Loneliness?. CyberPsychology Behavior 12:2, 219-223. [Abstract] [PDF] [PDF Plus]

3. Dianne M. Timm, Reynol Junco. 2008. Beyond the horizon. New Directions for Student Services 2008:124, 117-123. [CrossRef]

4. Shelia R. Cotten. 2008. Students' technology use and the impacts on well-being. New Directions for Student Services 2008:124, 55-70. [CrossRef]

5. Reynol Junco, Gail A. Cole-Avent. 2008. An introduction to technologies commonly used by college students. New Directions for Student Services 2008:124, 3-17. [CrossRef]

6. Bo Xie. 2008. Multimodal Computer-Mediated Communication and Social Support among Older Chinese Internet Users. Journal of Computer-Mediated Communication 13:3, 728-750. [CrossRef]

7. Patti M. Valkenburg, Jochen Peter. 2007. Online Communication and Adolescent Well-Being: Testing the Stimulation Versus the Displacement Hypothesis. Journal of Computer-Mediated Communication 12:4, 1169-1182. [CrossRef]

8. Dr. M. Kyle matsuba . 2006. Searching for Self and Relationships OnlineSearching for Self and Relationships Online. CyberPsychology Behavior 9:3, 275-284. [Abstract] [PDF] [PDF Plus]

9. Dr. Andrew J. Campbell, Steven R. Cumming, Ian Hughes . 2006. Internet Use by the Socially Fearful: Addiction or Therapy? Internet Use by the Socially Fearful: Addiction or Therapy?. CyberPsycbology Behavior 9:1, 69-81. [Abstract] [PDF] [PDF Plus]

10. Dr. , Ping Sun , Jennifer B. Unger, Paula H. Palmer, Peggy Gallaher, Chih-Ping Chou, Lourdes Baezconde-Garbanati, Steve Sussman, C. Anderson Johnson . 2005. Internet Accessibility and Usage among Urban Adolescents in Southern California: Implications for Web-Based Health ResearchInternet Accessibility and Usage among Urban Adolescents in Southern California: Implications for Web-Based Health Research. CyberPsychology Behavior 8:5, 441-453. [Abstract] [PDF] [PDF Plus]

11. Reiko Ando, Mieko Takahira, Akira Sakamoto. 2005. Effects of Internet Use on Junior High School Students' Loneliness and Social Support. The Japanese Journal of Personality 14:1, 69-79. [CrossRef]

12. Lauren Donchi, Susan Moore. 2004. It's a Boy Thing: The Role of the Internet in Young People's Psychological Wellbeing. Behaviour Change 21:2, 76-89. [CrossRef]

13. Elisabeth Engelberg, Lennart Sjöberg . 2004. Internet Use, Social Skills, and AdjustmentInternet Use, Social Skills, and Adjustment. CyberPsychology Behavior 7:1, 41-47. [Abstract] [PDF] [PDF Plus] 